\title{
Proton NMR Studies on the Conformation of the Pterin Cofactor Bound at the Active Site of Recombinant Human Tyrosine Hydroxylase
}

\author{
Aurora Martínez ${ }^{1 \S}$, Olga Vageli ${ }^{1}$, Wolfgang Pfleiderer $^{2}$ and Torgeir Flatmark ${ }^{1}$ \\ ${ }^{1}$ Department of Biochemistry and Molecular Biology, University of Bergen, Årstadveien 19, \\ N-5009 Bergen, Norway \\ ${ }^{2}$ Fakultät für Chemie, Universität Konstanz, Postfach 5560, D-78434 Konstanz, Germany
}

(Received January 12, 1998)

\begin{abstract}
Summary
The binding of L-erythro-7,8-dihydrobiopterin $\left(\mathrm{BH}_{2}\right)$ in the presence of $\mathrm{L}$-Phe to recombinant human tyrosine hydroxylase was studied by ${ }^{1} \mathrm{H}-\mathrm{NMR}$ spectroscopy. The distances $( \pm 1.3 \AA)$ from the active site metal were estimated to be 5.3-6.4 $\AA$ for observable protons of $\mathrm{BH}_{2}$ and 7.0-7.9 $\AA$ for L-Phe protons. Due to the lack of constraints from the pyrimidine ring in $\mathrm{BH}_{2}$, two families of conformers were computed, with an average distance from the $\mathrm{C} 4 \mathrm{a}$ in the pterin ring to the iron of $3.7 \AA$ (family $\mathrm{A}$ ) and $8.8 \AA$ (family $\mathrm{B}$ ). The conformers for 6-methyl-tetrahydropterin bound to the enzyme at near anaerobic conditions in the absence of L-Phe were also grouped into two families, with C4a-metal distances of 3.0-4.0 $\AA$ (A) and 7.0-7.5 $\AA$ (B). Based on the estimated conformation of the enzyme bound 5,6,7,8-tetrahydro3-methylpterin, family A of conformers was selected for both oxidized and reduced pterins. Our results indicate that the pterin does not coordinate to the iron, which seems to be involved both in the binding and activation of $\mathrm{O}_{2}$ and in the $\mathrm{C}-\mathrm{O}$ bond formation in the aromatic ring of the substrate.
\end{abstract}

Key words : Tyrosine hydroxylase, $(6 R)$-tetrahydrobiopterin, 7,8-dihydrobiopterin, Transferred NOESY, Paramagnetic NMR, Reaction mechanism

\section{Introduction}

Tyrosine hydroxylase (TH, EC 1.14.16.2) is a non-heme iron and tetrahydrobiopterin-dependent enzyme which catalyzes the hydroxylation of L-tyrosine (L-Tyr) to L-3,4-dihydroxyphenylalanine (L-

\footnotetext{
${ }^{\S}$ Author to whom correspondence should be addressed. Abbreviations

$\mathrm{BH}_{2}$, L-erytho-7,8-dihydrobiopterin; $\mathrm{BH}_{4},(6 R)$-L-erythro5,6,7,8-tetrahydrobiopterin; TH, tyrosine hydroxylase; TH1, human tyrosine hydroxylase, isoform 1; L-Phe, Lphenylalanine; 6- $\mathrm{MPH}_{4}, \quad 6$-methyl-tetrahydropterin; NOESY, nuclear Overhauser effect spectroscopy; TPPI, time proportional phase incrementation; TRNOESY, transferred nuclear Overhauser effect spectroscopy.
}

DOPA), the rate-limiting step in the biosynthesis of catecholamines $(1,2)$. The enzyme also catalyzes the hydroxylation of L-phenylalanine (L-Phe) to LTyr (3). The human enzyme exists as four isoforms (TH1-TH4) generated by alternative splicing events, and THI is the predominant form in the adrenal medulla and in the locus coeruleus and substantia nigra of the brain (4). TH1 is expressed in Escherichia coli as an homotetramer $(55.9 \mathrm{kDa}$ per subunit) and is purified as an apoenzyme which is activated (up to a 40-fold) by incorporation of a stoichiometric amount of $\mathrm{Fe}$ (II) (5). The enzyme is also competitively inhibited by other divalent metal ions, i.e. $\mathrm{Zn}(\mathrm{II}), \mathrm{Co}(\mathrm{II})$ and $\mathrm{Ni}(\mathrm{II})$ which bind to 
the same site as $\mathrm{Fe}$ (II) $(3,6)$. Although $\mathrm{Fe}$ (II) is an essential component of the active enzyme $(6,7)$, its mechanistic role in the hydroxylation reaction is not established. The identity of the putative hydroxylating species is also unknown, but the detection of a 4a-hydroxy-tetrahydropterin intermediate, released from the enzyme during catalysis (79), has suggested that a 4a-hydroperoxytetrahydropterin is likely to be formed in the oxygen-activation step. This hydroperoxy compound could serve either as the direct hydroxylating species through electrophilic addition to the aromatic ring of the substrate or as an intermediate to its formation $(7,10)$. The crystal structure of a truncated form of tyrosine hydroxylase has been recen- tly determined (11), which in combination with the elucidation of the conformation of the bound substrates will at last allow to establish the catalytic mechanism of the enzyme.

In a previous work (3) the conformation of the substrate (L-Phe) and its proximity to the active site metal was determined by NMR using THI reconstituted with $\mathrm{Co}(\mathrm{II})$ or $\mathrm{Zn}(\mathrm{II})$. It was shown that the aromatic ring was placed at the second coordination sphere of the metal and that $\mathrm{Fe}$ bound oxy or peroxy species may approach molecular contact with the $\mathrm{C} 3 / \mathrm{C} 4$ atoms of the ring. Preliminary data have also been obtained for the binding of the cofactor analogue 6-methyl-tetrahydropterin $\left(6-\mathrm{MPH}_{4}\right)(12)$ to $\mathrm{Co}(\mathrm{II})$-reconstituted THI in the absence of amino acid. In the present study the conformation of the oxidized form of the natural pterin cofactor L-erythro-7,8-dihydrobiopterin $\left(\mathrm{BH}_{2}\right)$ and its proximity to the active site metal in the presence of L-Phe, forming the catalytically inactive ternary complex [TH]-metal

$\mathrm{BH}_{2} \cdot$ L-Phe], was determined based on metalproton distances measured by the paramagnetic probe- $T_{1}$ method $(3,13)$ supplemented by NOE distance constraints, measured by two-dimensional transferred NOESY (TNOESY) $(14,15)$.

\section{Materials and Methods}

\section{Materials}

Before use, buffers and solutions of L-Phe (Sigma Chemical Co., St. Louis, MO), L- · erythro7,8-dihydrobiopterin $\left(\mathrm{BH}_{2}\right)$ (Dr. B. Schircks Laboratories, Jona, Switzerland) and 5,6,7,8-tetrahydro-3-methylpterin (see below) were passed through Chelex-100 ion exchange resin (Bio-Rad Laboratories, Richmond, CA). ${ }^{2} \mathrm{H}_{2} \mathrm{O}$ (99.96\%), free from paramagnetic impurities, was from Aldrich
(Aldrich Chemical Company, Inc., Milwaukee, Wi). Recombinant human tyrosine hydroxylase isoform 1 (TH1) was expressed in E. coli and purified to homogeneity as previously described (5). The concentration of the protein was determined by the absorbance at $280 \mathrm{~nm}\left(\in^{1 \%}=10.4 \mathrm{~cm}^{-1}\right)$ at $\mathrm{pH} 7.0$ (5). The purified preparations of THl contained about $0.02 \mathrm{iron} / \mathrm{subunit}$, as determined by atomic absorption spectroscopy and were considered to represent the apoenzyme (apo-THI).

\section{Synthesis of 5,6,7,8-tetrahydro-3-methylpterin}

A solution of 3 -methylpterin $(1.8 \mathrm{~g}, 0.01 \mathrm{~mol})$, prepared as described (16) in trifluoroacetic acid $(40 \mathrm{ml})$ was reduced catalytically with hydrogen in a shaking apparatus in the presence of $\mathrm{PtO}_{2}(0.2$ g) as catalyst. The theoretical uptake of 2 equivalents of hydrogen $(450 \mathrm{ml})$ was complete after 6 $h$. The solution was filtered under nitrogen to remove the catalyst. The brownish filtrate was concentrated in vacuum to a small volume and then treated with a saturated solution of methanolic $\mathrm{HCl}$. A solid precipitated, the yield of which can be increased by addition of little ether. The precipitate was filtered off and dried over $\mathrm{KOH}$ in a desiccator to give $1.71 \mathrm{~g}(63 \%)$ of a brownish crystal powder. UV $(0.1 \mathrm{~N} \mathrm{HCl}) \lambda_{\max } 264(\varepsilon 13764)$. ${ }^{1} \mathrm{H}$-NMR (D ${ }_{6}$-DMSO): 8.0 (bs, $\left.1 \mathrm{H}, \mathrm{H}-\mathrm{N}(8)\right) ; 4.2$ $\left(\mathrm{t}, 2 \mathrm{H}, \mathrm{H}_{2} \mathrm{C}(6) ; 3.5\left(\mathrm{t}, 2 \mathrm{H}, \mathrm{H}_{2} \mathrm{C}(7) ; 3.3(\mathrm{~s}, 3 \mathrm{H}\right.\right.$, $\mathrm{Me}(3))$. Anal. Calc. for $\mathrm{C}_{7} \mathrm{H}_{11} \mathrm{~N}_{5} \mathrm{O} \times 2 \mathrm{HCl} \times \mathrm{H}_{2}$ O (271.1): C 31.02, H 5.58, N 25.82; found: C $31.07, \mathrm{H} \mathrm{5.37,} \mathrm{N} \mathrm{25.58.} \mathrm{The} \mathrm{purity} \mathrm{of} \mathrm{the} \mathrm{5,6,7,}$ 8-tetrahydro-3-methylpterin was established both by ${ }^{1} \mathrm{H}-\mathrm{NMR}$ and by HPLC and UV detection as described (12). No other pterin in addition to the 5,6,7,8-tetrahydro-3-methylpterin was detected.

\section{Tyrosine hydroxylase assay}

TH activity was measured as described (17), with $25 \mu \mathrm{L}-\left[3,5{ }^{3} \mathrm{H}\right]$-tyrosine, $0.5 \mathrm{mM}(6 R)-\mathrm{L}-$ erythro-5,6,7,8-tetrahydrobiopterin $\left(\mathrm{BH}_{4}\right), 0.5$ $\mathrm{mg} / \mathrm{ml}$ catalase, $5 \mathrm{mM}$ dithiothreitol, and $20 \mu \mathrm{M}$ ferrous ammonium sulfate in $100 \mathrm{mM} \mathrm{NaHepes,}$ $\mathrm{pH}$ 7.0. The specific activity of purified THI was found to be $500 \pm 6 \mathrm{nmol}$ DOPA $\mathrm{min}^{-1} \mathrm{mg}^{-1}$ and the enzyme retained about $90 \%$ of its activity after prolonged NMR data acquisition (up to $24 \mathrm{~h}$ at $20^{\circ} \mathrm{C}$, see below).

\section{NMR measurements}

TH1 samples were initially prepared in $20 \mathrm{mM}$ NaHepes, $\mathrm{pH} 7.5$ and $0.15 \mathrm{M} \mathrm{NaCl}^{\text {. The sam- }}$ 
ples were then subjected to several cycles of dilution/concentration in an Amicon Centricon 30 microconcentrator in order to exchange the buffer to $0.1 \mathrm{M}$ deuterated K-phosphate, $0.1 \mathrm{M}$ $\mathrm{KCl}, \mathrm{pH}^{*}$ 7.4. The $\mathrm{pH}^{*}$ of the samples, determined with an Ingold electrode, represents the measured value in ${ }^{2} \mathrm{H}_{2} \mathrm{O}$.

The paramagnetic effects of the enzyme-bound $\mathrm{Co}$ (II) on the longitudinal $\left(1 / \mathrm{T}_{1}\right)$ (and the transverse $\left(1 / \mathrm{T}_{2}\right)$ ) relaxation rates of proton resonances of enzyme-bound ligands were measured on a Bruker AM 400- $\mathrm{MHz}$ spectrometer at a probe temperature of $20^{\circ} \mathrm{C}$. The samples $(0.5 \mathrm{ml})$ contained 0.05-0.1 mM TH1, $5 \mathrm{mM} \mathrm{BH}_{2}$ (or 5 $\mathrm{mM} \quad 5,6,7,8$-tetrahydro-3-methylpterin), $0.1 \quad \mathrm{M}$ $\mathrm{KCl}$ and $0.1 \mathrm{M}$ deuterated $\mathrm{K}$-phosphate buffer, $\mathrm{pH}^{*}$ 7.4. After $5 \mathrm{~min}$ incubation at $20^{\circ} \mathrm{C}, 5 \mathrm{mM}$ L-Phe was added (except for measurements with 5,6,7,8-tetrahydro-3-methylpterin). Then, successive aliquots of $\mathrm{CoCl}_{2}$ (up to $50 \mu \mathrm{M}$ ) were added and $T_{1}$-values were measured by the inversion recovery method, with acquisition parameters including $16 \mathrm{~K}$ data points, spectral width $3597 \mathrm{~Hz}$ and 8 transients per time increment with a 10-s delay $\left(>5 \quad T_{1}\right)$. The $T_{2}$-values of the $H 7$ proton resonance of $\mathrm{BH}_{2}$ were determined from the width of this resonance at half-height $\left(\Delta v_{1 / 2}\right)$, where $1 / \mathrm{T}_{2}=\pi \cdot \Delta v_{1 / 2}$. The paramagnetic effects of the enzyme-bound $\mathrm{Co}$ (II) on $1 / \mathrm{T}_{1}$ and $1 / \mathrm{T}_{2}$ were analyzed by plotting the increase in the relaxation rates as a function of the concentration of added $\mathrm{Co}(\mathrm{II})(5)$. The normalized paramagnetic contributions to the longitudinal $\left(1 / f \mathrm{~T}_{1 \mathrm{P}}\right)$ and transverse $\left(1 / f \Gamma_{2 p}\right)$ relaxation rates were calculated using a $K_{\mathrm{i}}$-value of $70 \mu \mathrm{M}$ and $K_{\mathrm{m}}$-value of $85 \mu \mathrm{M}$ for the binding of $\mathrm{BH}_{2}$ and L-Phe, respectively (3). THl (0.1 $\mathrm{mM}$ subunit) was calculated to be $>98 \%$ saturated with $\mathrm{BH}_{2}$ and LPhe (added at $5 \mathrm{mM}$ ) for determining the normalized relaxation rates. For the binding of $5,6,7$, 8-tetrahydro-3-methylpterin (added at $5 \mathrm{mM}$ ), with a $K_{\mathrm{m}}$-value of $685 \mu \mathrm{M}$ (see Results), THl (50 $\mu \mathrm{M}$ subunit) was calculated to be $94 \%$ saturated. The $1 / f T_{1 P^{-v a l u e s}}$ together with the effective correlation time for the electron-nuclear dipolar interaction $\left(\tau_{\mathrm{C}}=1.8 \pm 0.1 \mathrm{ps}\right)$, determined earlier for the [TH1-Co(II) $\left.\cdot \mathrm{BH}_{2} \cdot \mathrm{L}-\mathrm{Phe}\right] \mathrm{com}-$ plex (3), were used to calculate the metal-proton distances based on the general theory (13). Errors in the absolute distances include an approx. $15 \%$ contribution from the $C$-value $(895 \pm 125)$ arising from the $g$ tensor for high-spin $\mathrm{Co}(\mathrm{II})$ (13) and an approx. 5\% contribution due to errors in $1 / f \mathrm{~T}_{1 \mathrm{P}}$ and $\tau_{\mathrm{C}}$. However, errors in the relative dis- tances are practically limited to $3 \%(3)$.

Transferred NOEs from the bound to the free state of both pterin and amino acid substrates were measured from NOESY spectra on a Bruker $\mathrm{AM} \quad 400-\mathrm{MHz}$ spectrometer at $20^{\circ} \mathrm{C}$. The samples $(0.5 \mathrm{ml})$ contained $0.3 \mathrm{mM} \mathrm{TH}, 5 \mathrm{mM}$ $\mathrm{BH}_{2}, 0.3 \mathrm{mM} \mathrm{ZnCl}, 0.1 \mathrm{M} \mathrm{KCl}$ and $0.1 \mathrm{M}$ deuterated K-phosphate, $\mathrm{pH}^{*}$ 7.4. After $5 \mathrm{~min}$ incubation at $20^{\circ} \mathrm{C}, 5 \mathrm{mM} \mathrm{L}$-Phe was added. A similar fraction of bound $\mathrm{BH}_{2}$ and L-Phe $\left(\mathrm{p}_{\mathrm{B}} \approx 0.06\right)$ was estimated at these concentrations of enzyme and ligands and this $p_{B}$-value was found to be optimal to obtain cross-peak intensities significantly above the noise level and to reduce spin diffusion effects (14). NOESY spectra were acquired at different mixing times (50, 100, 150, $250 \mathrm{~ms})$, in the time-proportional phase-sensitive mode using TPPI for quadrature detection in $\omega_{1}$ and with suppression of the residual water signal. Acquisition parameters included 3 -s relaxation delay, sweep width of $3597 \mathrm{~Hz}$ and 16 scans per $t_{1}$ value. The $2 \mathrm{D}$-raw data sets of $512 \times 2048$ (TPPI) time domain data points $\left(t_{1}, t_{2}\right)$ were processed on a MicroVax 2000 using the FT-NMR processing software (Hare Research, Inc.). Processing parameters included zero-filling in $t_{1}$, sine-bell apodization shifted by $\pi / 4$ in both directions and a 3rd order polynomial baseline correction after Fourier transformation. Matrices of $1024 \times 1024$ points real data were then obtained.

Both $\mathrm{BH}_{2}$ and L-Phe were shown to be in fast exchange (see ref. 3 and Results) between the enzyme-bound and free states (on the chemical shift time scale) and the average signals in the NMR spectra represent

$$
\delta_{\mathrm{OBS}}=\mathrm{P}_{\mathrm{F}} \delta_{\mathrm{F}}+\mathrm{p}_{\mathrm{B}} \delta_{\mathrm{B}}
$$

where $\delta_{\mathrm{ORS}}$ is the observed chemical shift, $\delta_{\mathrm{F}}$ and $\delta_{B}$, the chemical shift for the signals of the free and bound ligand, respectively, and $p_{F}$ and $p_{B}$, the fraction of free and bound ligand, respectively. Since $p_{\mathrm{B}}$ is small $(\approx 0.06)$, both $\delta_{\mathrm{OBS}}$ and the observed line width are dominated by the free ligand concentration. For a system in fast chemical exchange in which $\mathrm{Wij}_{\mathrm{F}}<<\mathrm{Wij}_{\mathrm{B}}$ (cross-relaxation rates between spins $i$ and $j$ in the free and bound state, respectively), the transferred NOE cross-peak intensities (aij) at mixing time $\left(\tau_{\mathrm{m}}\right)$ are given by

$$
\text { aij }\left(\tau_{\mathrm{m}}\right) \approx-\left(\mathrm{p}_{\mathrm{B}} \mathrm{Wij}_{\mathrm{B}}\right) \tau_{\mathrm{m}}
$$

with $\mathrm{Wij}_{\mathrm{B}} \propto 1 / \mathrm{rij}_{\mathrm{B}}{ }^{6}$ and $r$ being the distance between spins $i$ and $j$ in the bound state $(18,19)$.

Intensities of transferred NOE cross-peaks were 
measured by volume integration, and interproton distances were calculated at each mixing time using as a reference the distance of $2.46 \pm 0.02 \AA$ between the $\mathrm{H} 2,6$ and the $\mathrm{H} 3,5$ protons of $\mathrm{L}$ Phe as measured by neutron diffraction (20) and extrapolation to zero mixing time to minimize spin-diffusion effects. Distances from aliphatic to degenerate pairs of aromatic protons in L-Phe were treated as single proton-proton interactions.

\section{Molecular modeling}

Conformation analyses were performed on an Indy workstation (Silicon Graphics, Inc.) using the programs Insight II and NMRchitect (Biosym Technologies, San Diego, CA). A series of conformers were generated from metal-proton and NOE distance constraints supplemented by chirality constrains by the DGII software package. Lower and upper limits for the metal-proton distances were set by considering the experimental error for relative distances to the metal (about $3 \%$, see above), while the error limits for interproton distances ( $r i j)$ were set to $\pm 0.2 \AA$ if $r i j \leq 3.0 \AA$, to \pm $0.3 \AA$ if $3.0 \AA \leq r i j \leq 4.0 \AA$ and to $0.4 \AA$ if $r i j \geq 4.0$ A. Degenerated protons were treated considering an average distance from their center of mass. Calculations included triangle bound smoothing and embedding in four dimensions using metrized distance matrices $(21,22)$. The embedded set of coordinates were refined using simulated annealing optimization followed by a conjugate gradient minimization of the error function (22) to obtain the converged distance geometry based structures.

\section{Results}

In order to determine the conformation of the pterin and the amino acid substrate (L-Phe) when simultaneously bound to $\operatorname{Co}(\mathrm{II})$-reconstituted TH1 the oxidized form of the natural cofactor, Lerythro-7,8-dihydrobiopterin $\left(\mathrm{BH}_{2}\right)$, was used as a catalytically inactive analogue. Reduced pterin cofactors could not be used simultaneously with L-Phe due to the presence of some residual iron (trace amounts) in apo-THI (see Materials and Methods), which results in some catalytic turnover. $\mathrm{BH}_{2}$ is stable at neutral $\mathrm{pH}$ and binds to the enzyme as a competitive inhibitor versus $\mathrm{BH}_{4}$ (3). The advantages of using L-Phe instead of L-Tyr as the amino acid substrate have already been discussed (3).
Paramagnetic effects of enzyme-bound Co(II) on the relaxation rates of the proton resonances of $\mathrm{BH}_{2}$ and $\mathrm{L}-\mathrm{Phe}$

In the $400-\mathrm{MHz}^{1} \mathrm{H}-\mathrm{NMR}$ spectrum of a mixture of $\mathrm{BH}_{2}$ and $\mathrm{L}-\mathrm{Phe}$ in the presence of apoTH1, proton signals from the pterin and the amino acid are observed beyond the protein envelope and, except for the overlapping $\mathrm{H} \alpha$ proton of L-Phe and the $\mathrm{H} 2$ ' from $\mathrm{BH}_{2}$, the proton signals are well separated (Figure 1 ). We have previously shown that both $\mathrm{Co}$ (II) and $\mathrm{Zn}$ (II) bind to apo-THl with high affinity competitive to $\mathrm{Fe}(\mathrm{II})\left(\mathrm{K}_{\mathrm{d}} \leq 1 \mu \mathrm{M}\right)(5)$. Moreover, the binding of both $\mathrm{Co}(\mathrm{II})$ and $\mathrm{Zn}(\mathrm{II})$ was shown to be independent and mutually exclusive at the $\mathrm{Fe}(\mathrm{II})$ binding site (3). On addition of $\mathrm{Co}$ (II) (up to 50 $\mu \mathrm{M}$ ) to the apoenzyme in the presence of $\mathrm{BH}_{2}$ and L-Phe forming a catalytically inactive complex [TH1-Co(II) $\cdot \mathrm{BH}_{2} \cdot$ Phe], a decrease in $1 / \mathrm{T}_{1}$ and $1 / T_{2}$ of the proton resonances of both ligands was observed. By contrast, reconstitution of apo-THl with diamagnetic $\mathrm{Zn}$ (II) had no effect on the relaxation rates of the ligand resonances (data not shown). Dopamine has been shown to bind to $\mathrm{TH} l$ competitively to the pterin cofactor (23); after addition of $0.2 \mathrm{mM}$ dopamine to the samples the paramagnetic contributions to the relaxation of $\mathrm{BH}_{2}$ protons was eliminated, indicating a total displacement of $\mathrm{BH}_{2}$ and that the enzyme-bound $\mathrm{Co}(\mathrm{II})$ has no paramagnetic effect on free $\mathrm{BH}_{2}$. Total displacement of $\mathrm{BH}_{2}$ from the
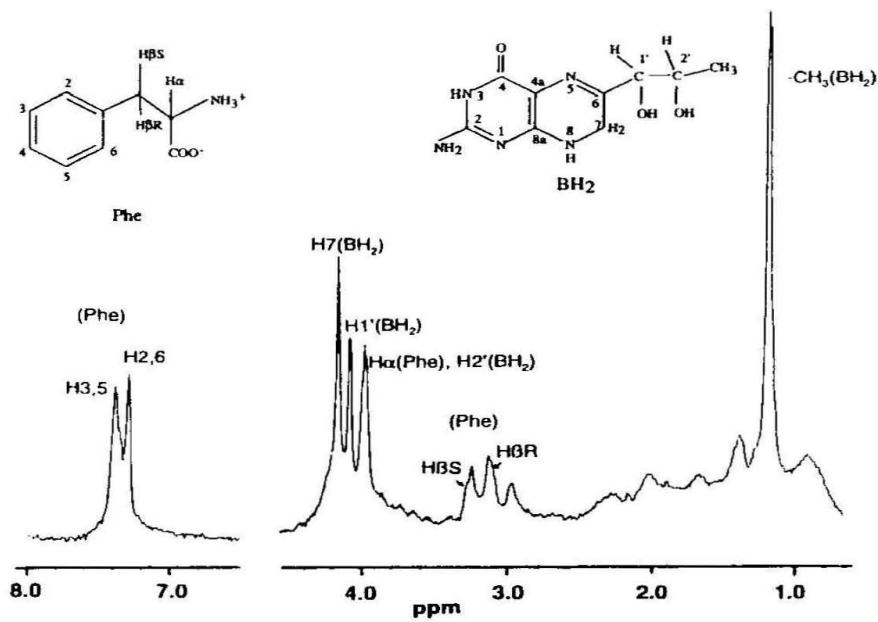

Figure 1. ${ }^{1} \mathrm{H}-\mathrm{NMR}$ spectrum of L-Phe and L-erythro-7, 8 -dihydrobiopterin $\left(\mathrm{BH}_{2}\right)$ in the presence of apo-THI. The $400-\mathrm{MHz}{ }^{1} \mathrm{H}-\mathrm{NMR}$ spectrum (100 transients) was taken at $273 \mathrm{~K}$ in samples $(0.5 \mathrm{ml})$ prepared in $\mathrm{D}_{2} \mathrm{O}$ containing $0.1 \mathrm{mM} \mathrm{THl}, 5 \mathrm{mM} \mathrm{BH}, 5 \mathrm{mM}$ L-Phe, $0.1 \mathrm{M}$ $\mathrm{KCl}$ and $0.1 \mathrm{M}$ deuterated $\mathrm{K}$-phosphate buffer, $\mathrm{pH}^{\star}$ 7.4. 
Table 1. Calculated distances from $\mathrm{Co}(\mathrm{II})$ to observable protons of $\mathrm{BH}_{2}$ in the $\left[\mathrm{TH}-\mathrm{Co}(\mathrm{II}) \cdot \mathrm{BH}_{2} \cdot\right.$ Phe] complex

\begin{tabular}{cccc}
\hline \hline nucleus & $\delta(\mathrm{ppm})^{a}$ & $\mathrm{l} / f \mathrm{~T}_{1 \mathrm{P}}\left(\mathrm{s}^{-1}\right)$ & $r(\AA)^{b}$ \\
\hline $\mathrm{H}^{c}$ & 4.17 & 37 & $6.2 \pm 1.1$ \\
$\mathrm{HI}$ & 4.08 & 125 & $5.3 \pm 1.0$ \\
$\mathrm{CH}_{3}$ & 1.20 & 43.4 & $6.4 \pm 1.3$ \\
\hline
\end{tabular}

${ }^{a}$ From external sodium 3-(trimethylsilyl)-propionate.

${ }^{h}$ Total errors in the absolute distances $r$, include contributions of $6 \%$ from errors in $1 / f \mathrm{~T}_{\mathrm{IP}}$ and $\tau_{\mathrm{C}}$, and contributions of $14 \%$ from the assumption that the value of $g$ for high-spin $\mathrm{Co}(11)$ is $4 \pm 2$ (15).

'Average position of the two $\mathrm{H} 7$ protons.

ternary complex was also observed after addition of $500 \mu \mathrm{M} \mathrm{BH} \mathrm{BH}_{4}$. Thus, the outer-sphere contribution to the relaxation rates of $\mathrm{BH}_{2}$ in the complex [THI-Co(II) $\mathrm{BH}_{2} \cdot$ Phe $]$ was calculated to be equal to zero.

The $1 / f \mathrm{~T}_{1 \mathrm{p}}$-values for $\mathrm{BH}_{2}$ protons and the distances from the paramagnetic center to these protons (except for the $\mathrm{H}^{2}$ proton whose signal overlaps with that of the $\mathrm{H} \alpha$ proton of $\mathrm{L}-\mathrm{Phe}$ ) were then calculated (see Materials and Methods and ref. 3) (Table 1). The linearity of the paramagnetic effects with the $\mathrm{Co}(\mathrm{II})$ concentration (data not shown and ref. 3 ) and the inequality of the $1 / f T_{1 P}$ values for the different protons (Table 1) argue against significant contributions of spin diffusion to the relaxation rates. The $1 / f \mathrm{~T}_{2 \mathrm{P}}$-value for the $\mathrm{H} 7$ proton of $\mathrm{BH}_{2}$ was found to be $1664 \pm 97 \mathrm{~s}^{-1}$, an order of magnitude greater than its $1 / f T_{1 p}$-value, indicating that the lifetime of the complex $\left(\tau_{\mathrm{M}}\right)$ contributes little to the $\mathrm{T}_{1 \mathrm{P}}$-values and can be excluded in the calculation of distances. Distances from the paramagnetic center to the protons of L-Phe in the complex [THI-Co(II) - $\mathrm{BH}_{2} \cdot$ Phe] were also calculated, and the values obtained ranged from $7.0( \pm 1.3) \AA$ for the aromatic protons to 7.9 ( \pm 1.4$) \AA$ for the $H \beta$ protons, in good agreement with previous calculations (3).

\section{Intramolecular nuclear Overhauser effects in the enzyme-bound $\mathrm{BH}_{2}$ and L-Phe}

The intramolecular proton distances of the bound $\mathrm{BH}_{2}$ and $\mathrm{L}$-Phe were measured from TRNOESY spectra of the complex [TH1-Zn(II) . $\mathrm{BH}_{2} \cdot$ Phe], since $\mathrm{Zn}(\mathrm{II})$ is diamagnetic and binds with high affinity to apo-THl $\left(K_{\mathrm{d}}=0.3 \mu \mathrm{M}\right)$ at the same site as $\mathrm{Fe}$ (II) $(3,5)$. Transferred NOEs from the bound to the free state were observed for both $\mathrm{BH}_{2}$ and L-Phe as cross-peaks in the NOESY spectra, reflecting negative NOEs (Figure 2 ). A similar value of $\mathrm{p}_{\mathrm{B}}$ for both ligands also in-

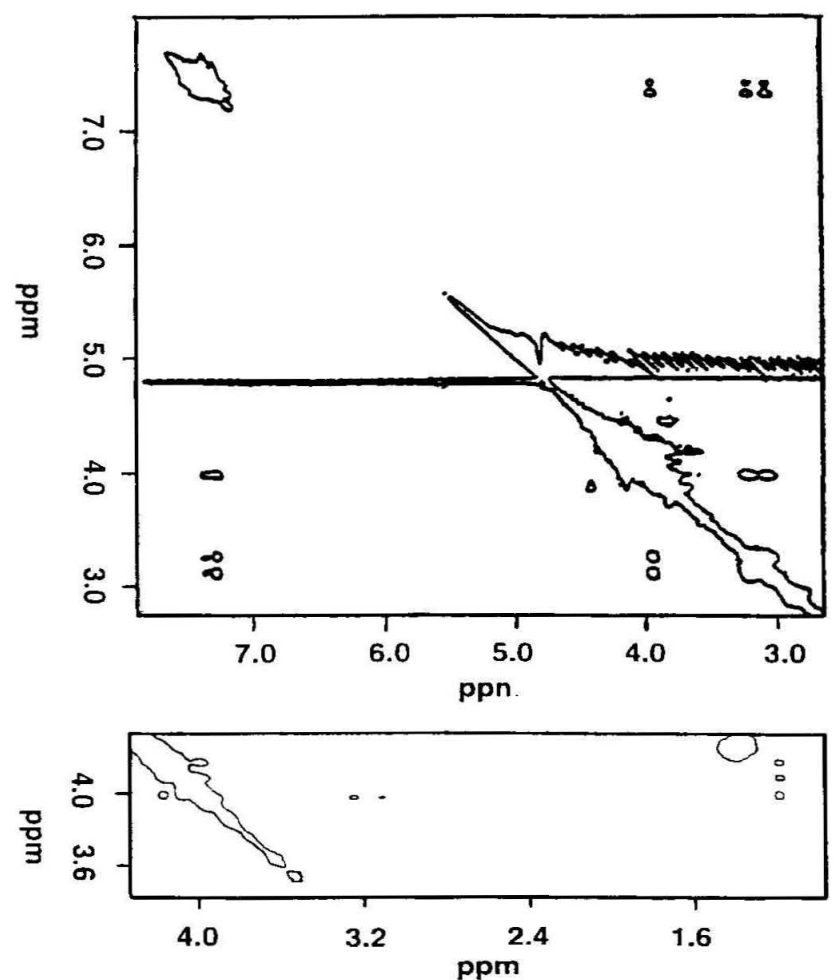

Figure 2. Two-dimensional nuclear Overhauser effect (NOESY) spectra of L-Phe and L-erythro-7,8-dihydrobiopterin $\left(\mathrm{BH}_{2}\right)$ in the presence of TH1. The $400-\mathrm{MHz}{ }^{1} \mathrm{H}-$ NMR spectra were taken at $273 \mathrm{~K}$ in samples $(0.5 \mathrm{ml})$ prepared in $\mathrm{D}_{2} \mathrm{O}$ containing $0.3 \mathrm{mM}$ THI, $5 \mathrm{mM} \mathrm{BH}_{2}, 5$ $\mathrm{mM}$ L-Phe, $0.3 \mathrm{mM} \mathrm{ZnCl}_{2}, 0.1 \mathrm{M} \mathrm{KCl}$ and $0.1 \mathrm{M}$ deuterated K-phosphate at $\mathrm{pH}^{\star}$ 7.4. The mixing time was $100 \mathrm{~ms}$; other parameters given in the Materials and Methods section. (Upper) Region showing cross-peaks between resonances of L-Phe. (Lower) Region showing cross-peaks between the $\mathrm{H} 7, \mathrm{Hl}^{\prime}$ and $\mathrm{H}^{\prime}$ and the methyl resonance of $\mathrm{BH}_{2}$.

dicates that the cross-relaxation rate of the $\mathrm{H} 2,6$ $\mathrm{H} 3,5$ protons of $\mathrm{L}-\mathrm{Phe}$, separated by $2.46 \pm 0.02$ $\AA$ (20), can be used as a reference to calculate the intramolecular proton distances both in $\mathrm{BH}_{2}$ and L-Phe (Table 2).

We have also looked for intermolecular interactions between $\mathrm{BH}_{2}$ and L-Phe in the NOESY spectra. However, the intensity of cross-peaks at the expected ppm values for these interactions was at the noise level of the protein cross-peaks, which precludes their unambiguous assignment to intermolecular interaction between the substrate and the pterin. Without distance constraints between L-Phe and $\mathrm{BH}_{2}$ an infinite number of positions may be adopted by both ligands around the active site metal and a plausible structural model of L-Phe and $\mathrm{BH}_{2}$ simultaneously bound to the enzyme could not be computed. 
Table 2. Calculated interproton distances in the [TH]$\left.\mathrm{Zn}(\mathrm{II}) \cdot \mathrm{BH}_{2} \cdot \mathrm{Phe}\right]$ complex based on NOESY spectra

\begin{tabular}{ll}
\hline \hline Proton pair & Distances $(\AA)$ \\
\hline$L-P h e:$ & \\
$\mathrm{H} 3,5-\mathrm{H} 2,6$ & $2.46 \pm 0.02^{a}$ \\
$\mathrm{H} 2,6-\mathrm{H} \alpha$ & $3.73 \pm 0.3$ \\
$\mathrm{H} 3,5-\mathrm{H} \alpha$ & $4.34 \pm 0.4$ \\
$\mathrm{H} 2,6-\mathrm{H} \beta$ (pro-S) & $3.83 \pm 0.3$ \\
$\mathrm{H} 2,6-\mathrm{H} \beta$ (pro-R) & $3.61 \pm 0.3$ \\
$\mathrm{H} \alpha-\mathrm{H} \beta$ (pro-S) & $3.56 \pm 0.3$ \\
$\mathrm{H} \alpha-\mathrm{H} \beta$ (pro-R) & $3.61 \pm 0.3$ \\
$B H_{2}:$ & \\
$\mathrm{H} 1^{\prime}-\mathrm{CH}{ }_{3}$ & $3.39 \pm 0.3$ \\
$\mathrm{H} 1^{\prime}-\mathrm{H} 7^{b}$ & $2.72 \pm 0.2$ \\
$\mathrm{HI}{ }^{\prime}-\mathrm{H} 2^{\prime}$ & $2.63 \pm 0.2$ \\
$\mathrm{H}^{b}-\mathrm{H} 2^{\prime}$ & $3.08 \pm 0.3$ \\
$\mathrm{H} 7^{\prime}-\mathrm{H} 1^{\prime}$ & $2.50 \pm 0.2$ \\
\hline
\end{tabular}

${ }^{a}$ Internal standard from neutron diffraction (26).

${ }^{h}$ Average position of the two $\mathrm{H} 7$ protons.

\section{Molecular modeling of bound pterins}

$\mathrm{BH}_{2}$ was built within the Builder module (Insight II) and its covalent geometry (bond lengths, angles, planarity of the rings) was optimized using the Mopac module with the MNDO framework. Distance geometry calculations for $\mathrm{BH}_{2}$ were performed using the three measured metal-proton distances (Table 1) and the five interproton distance constraints (Table 2) supplemented by two chirality constraints, $\mathrm{R}$ and $\mathrm{S}$, for the $\mathrm{C} \mathbf{1}^{\prime}$ and $\mathrm{C} 2{ }^{\prime}$ chiral centers (L-erythro-1',2'-dihydroxypropyl), respectively. Thirty sets of coordinates were computed in the embedding step of the calculation and refined (22). The refined set of structures was analyzed for the presence of chiral and distance constraints violations as well as covalent geometry violations. Three conformers with more than two violations of distance restraints were excluded, while for the rest of the conformers violations were limited to $<0.2 \AA$ and were all accepted. Two families of conformers ( $A$ and $B$ ) could be discerned (Figures $3 \mathrm{~A}$ and $3 \mathrm{~B}$ ), the major difference between the two being the orientation of the pterin rings towards the metal at the active site. This distance was shorter in family $\mathrm{A}$ (C4a is at 3.6-4.1 $\AA, \mathrm{N} 5$ at 3.3-3.8 $\AA$ and $\mathrm{O} 4$ at 3.3-4.1 $\AA$ from the metal) than in family $\mathrm{B}(\mathrm{C} 4 \mathrm{a}$ is at $8.6-9.0$ $\AA$, N5 at 7.8-8.1 $\AA$, and $\mathrm{O} 4$ at 10.7-11 $\AA$ from the metal). For all the conformations it was determined that the dihedral angle $(\Theta)$ around the C1'-C2' bond for the two hydroxyl groups in the side-chain at $\mathrm{C} 6$ was $-75^{\circ}$ to $-83^{\circ}$.

Assuming that the dihydroxypropyl side-chain at $\mathrm{C} 6$ has the same conformation in both enzyme-

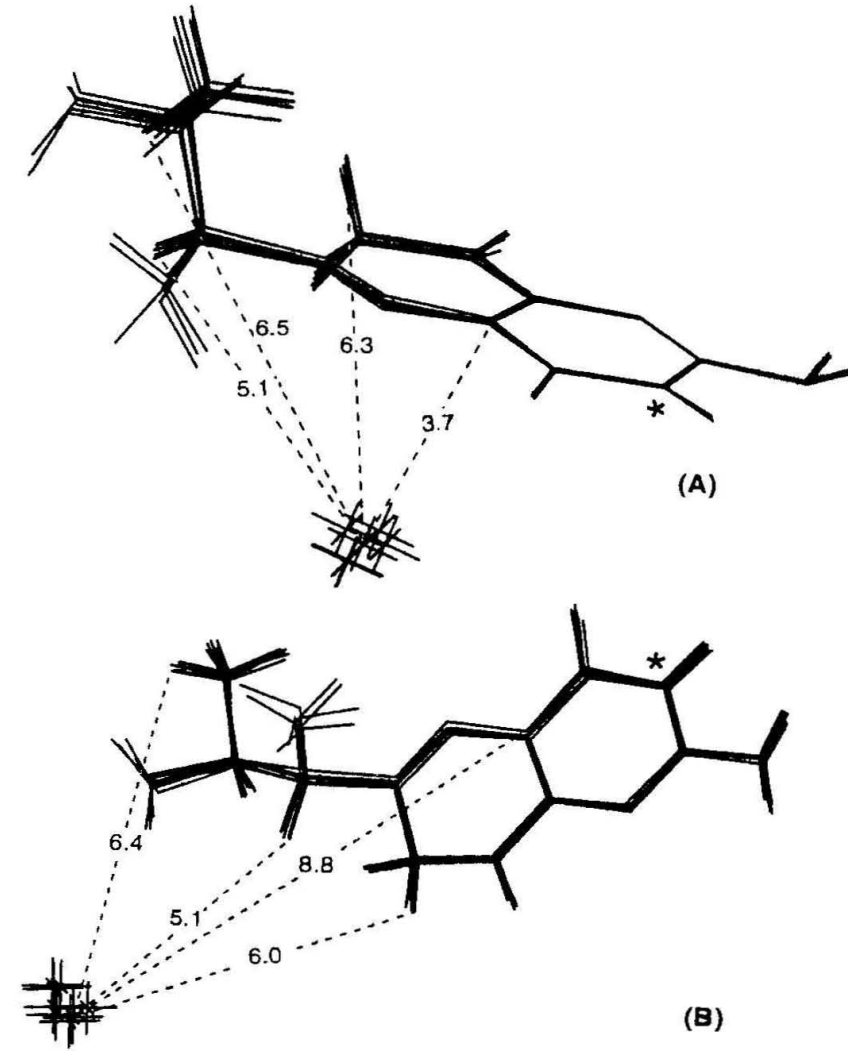

Figure 3. Conformations of L-erythro-7,8-dihydrobiopterin $\left(\mathrm{BH}_{2}\right)$ bound at the active site of metal $(\mathrm{Co}$ (II) or $\mathrm{Zn}(\mathrm{II}))$-reconstituted $\mathrm{TH} \mathrm{l}$ based on the experimental distances given in Tables 1 and 2 . Family A (A) and family $\mathrm{B}$ (B), shorter and longer distance from the pteridin ring to the metal ion, respectively (see Results), with the distances to the metal (in $\AA$ ) for one conformer in each family. The asterisk shows the position of the N3.

bound $\mathrm{BH}_{2}$ and $\left(6 R, 1^{\prime} \mathrm{R}, 2^{\prime} S\right)-6$-( $1^{\prime}, 2^{\prime}$-dihydroxypropyl)-5,6,7,8-tetrahydropterin $\left(\mathrm{BH}_{4}\right)$, we have also modeled the conformation of $\mathrm{BH}_{4}$ bound to TH1. The ring was built according to the structure determined by Matsuura et al. (24) and Williams and Storm (25) and the torsion angles [OO2'$\left.\mathrm{C} 2^{\prime}-\mathrm{Cl}^{\prime}-\mathrm{Ol}^{\prime}\right]$ and $\left[\mathrm{C}^{\prime}-\mathrm{C}^{\prime}{ }^{\prime}-\mathrm{Cl}^{\prime}-\mathrm{C} 6\right]$ were set to the corresponding values measured for the $\mathrm{TH} 1$ bound $\mathrm{BH}_{2}$. Two families of $\mathrm{BH}_{4}$ conformers (A and B) were also obtained, with similar distances from $\mathrm{C} 4 \mathrm{a}$ to the metal as calculated for the $\mathrm{BH}_{2}$ conformers (se above).

We have previously obtained data on the binding of the synthetic pterin cofactor $(6 R, S)$-methyltetrahydropterin $\left(6-\mathrm{MPH}_{4}\right)$ to THl at near anaerobic conditions in the absence of amino acid substrate (12). The distances between the metal and the H7R, H7S, H6 and methyl protons at C6 of $6-\mathrm{MPH}_{4}$ were calculated to range from 3.8 $( \pm 0.6) \AA$ to $5.3( \pm 0.9) \AA$. With these distances 
we modeled the conformation of TH1-bound 6$\mathrm{MPH}_{4}$ and compare it with that of $\mathrm{BH}_{2}$. The structure of the pterin ring of $6-\mathrm{MPH}_{4}$ was built according to the proposed structure of several tetrahydropterin salts as determined by $\mathrm{X}$-ray diffraction $(26,27)$ and high resolution NMR experiments (25), in which the C7 at the pyrazinering is nearly coplanar with the pyrimidine ring and the $\mathrm{N} 8$ atom essentially $\mathrm{sp}^{2}$ hybridized. The forty accepted conformers were also grouped into two families, i.e. family $\mathrm{A}$ with $\mathrm{C} 4 \mathrm{a}-\mathrm{metal}$ distances ranging from 3.0 to $4.0 \AA$ (Figure $4 \mathrm{~A}$ ) and family $\mathrm{B}$ in which this distance ranges from 7.0 to $7.5 \AA$ (Figure 4B). Both families included conformers with equatorial and axial positions of the methyl group at $\mathrm{C} 6$, since both solutions are within the experimental error for the relative metal-proton distances. However, from previous ${ }^{1} \mathrm{H}-\mathrm{NMR}$ studies it has been shown that the methyl at C6 prefers equatorial-like orientations (25), as shown in Figure 4A.

In order to investigate if the ambiguity in the distances from the pterin ring to the metal for
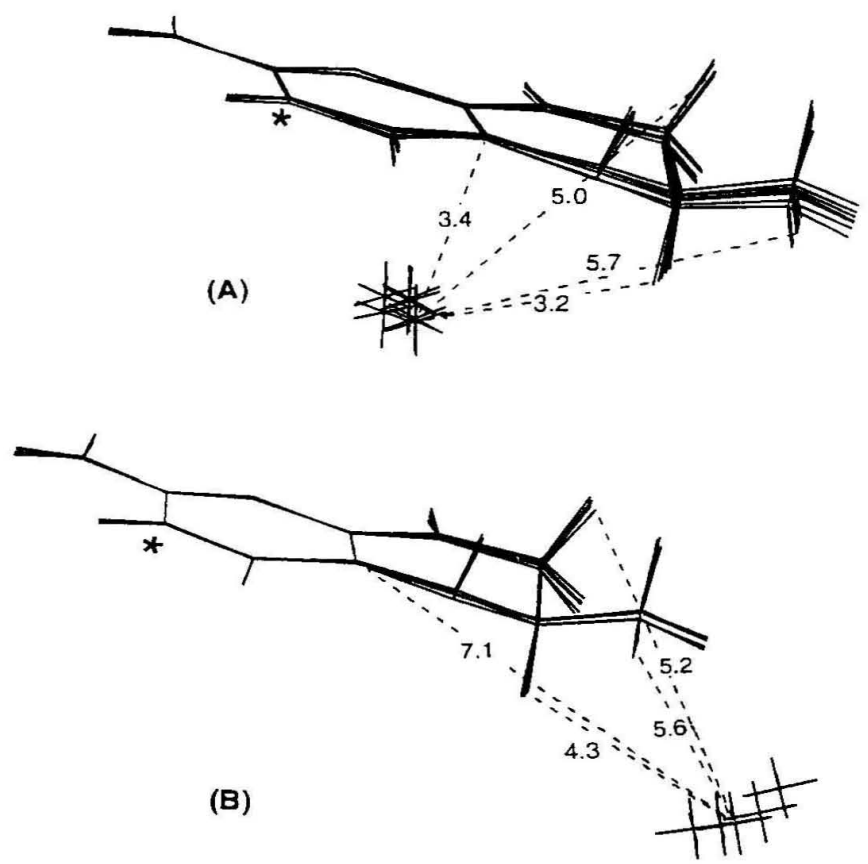

Figure 4. Conformations of 6-methyltetrahydropterin (6$\mathrm{MPH}_{4}$ ) bound at the active site of $\mathrm{Co}(\mathrm{II})$-reconstituted THl based on the experimental distances measured in ref. 16. Family A (A) and family B (B), shorter and longer distance from the pteridin ring to the metal ion, respectively (see Results and Discussion), with equatorial position for the methyl group at C6. For one conformer in each family, the distances in $\AA$ to the metal are shown. The asterisk shows the position of the N3. both $\mathrm{BH}_{2}$ and $6-\mathrm{MPH}_{4}$ is a result of the lack of distance restrains from the pyrimidine ring, we synthesized 5,6,7,8-tetrahydro-3-methylpterin, with stable protons at this ring. This pterin had cofactor activity with $K_{\mathrm{m}}=685 \pm 40 \mathrm{mM}$ and $V_{\max }=$ $15 \pm 1 \mathrm{nmol}$ L-DOPA $\mathrm{min}^{-1} \mathrm{mg}^{-1}$ (3\% of the activity with $\mathrm{BH}_{4}$ as cofactor and remained reduced in $\mathrm{D}_{2} \mathrm{O}$ even in the presence of $50 \mu \mathrm{M}$ apo-THI (Figure 5). On addition of $\mathrm{Co}$ (II) (up to $30 \mu \mathrm{M}$ ) to this sample a decrease in $1 / \mathrm{T}_{1}$ and $\mathrm{l} / \mathrm{T}_{2}$ of the proton resonances was observed and the distances from 5,6,7,8-tetrahydro-3-methylpterin protons to the paramagnetic center were estimated (Table 3 ). On modeling the conformation of the enzymebound 5,6,7,8-tetrahydro-3-methylpterin we found that the distance between the $\mathrm{Co}$ (II) in THI and the methyl was only compatible with conformers in which $\mathrm{C} 4 \mathrm{a}$ is separated $4.0-4.5 \AA$ from the metal, equivalent to family $\mathrm{A}$ of conformers for both $\mathrm{BH}_{2}$ and 6- $\mathrm{MPH}_{4}$ (see Figures 3 and 4).

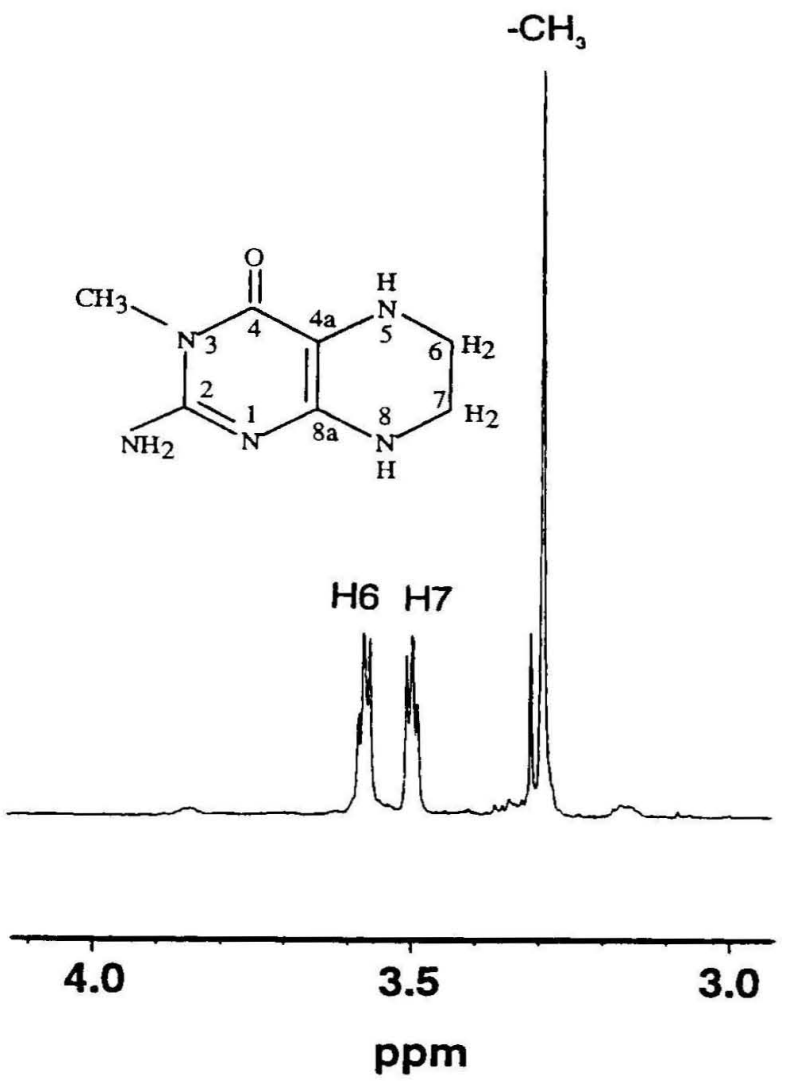

Figure 5. 'H-NMR spectrum of 5,6,7,8-tetrahydro-3methylpterin in the presence of apo-THI. The 400$\mathrm{MHz}{ }^{1} \mathrm{H}-\mathrm{NMR}$ spectrum (25 transients) was taken at $273 \mathrm{~K}$ in samples $(0.5 \mathrm{ml})$ prepared in $\mathrm{D}_{2} \mathrm{O}$ containing $0.05 \mathrm{mM}$ THI and $5 \mathrm{mM} 5,6,7,8$-tetrahydro-3methylpterin. 
Table 3. Calculated distances from $\mathrm{Co}(\mathrm{II})$ to protons of $5,6,7,8$-tetrahydro-3-methylpterin in the [TH1-Co(II) 5 , 6,7,8-tetrahydro-3-methylpterin] complex

\begin{tabular}{lccc}
\hline nucleus & $\delta(\mathrm{ppm})^{a}$ & $1 / f \mathrm{~T}_{1 \mathrm{p}}\left(\mathrm{s}^{1}\right)$ & $r(\AA)^{b}$ \\
\hline $\mathrm{H} 6$ & 4.17 & 90.0 & $5.6 \pm 1.0$ \\
$\mathrm{H}^{c}$ & 3.50 & 22.0 & $7.1 \pm 1.4$ \\
$\mathrm{CH}_{3}(\mathrm{~N} 3)$ & 3.29 & 23.4 & $7.0 \pm 1.3$ \\
\hline
\end{tabular}

${ }^{a, b}$ See Table 1 .

\section{Discussion}

In the present study the conformation of pterins $\left(\mathrm{BH}_{2}\right.$ and $\left.6-\mathrm{MPH}_{4}\right)$ when bound to the active site of metal-reconstituted $\mathrm{TH}$ l has been computed based on ${ }^{1} H-N M R$ experiments. The binding of $\mathrm{BH}_{2}$ was studied in the presence of $\mathrm{L}$ Phe as amino acid substrate and the conformation of enzyme-bound L-Phe obtained in an earlier study (3) was confirmed. Two distance geometry solutions (families A and B) satisfying the NMR data sets were obtained for the conformation of $\mathrm{BH}_{2}$ (and by assumption also for $\mathrm{BH}_{4}$ ), as well as for $6-\mathrm{MPH}_{4}$ bound in the absence of L-Phe. This ambiguity seems to result from the lack of distance restrains from the pyrimidine ring. Since the tetrahydropterin reduces the enzyme-bound $\mathrm{Fe}$ (III) to $\mathrm{Fe}$ (II) in $\mathrm{TH}$, both in the presence and absence of amino acid substrate (28), and $\mathrm{BH}_{4}$ is able to displace dopamine directly coordinated at the active site iron in THI (23), it is likely that the pterin binds at a distance from the metal corresponding to that in the family A of conformers. This is further supported by the conformation obtained for enzyme-bound 5,6,7,8-tetrahydro-3methylpterin. The estimated distances from the metal to the pterin ring are slightly different depending on the pterin analogue used and are shorter for $6-\mathrm{MPH}_{4}$, which has good cofactor activity $(1,2,14)$, and longest for 5,6,7,8-tetrahydro3 -methylpterin, which shows very low affinity and low cofactor activity (this work). These differences in the metal-pterin ring distances for the various cofactor analogues may result from the experimental error associated to the determination of absolute metal-proton distances by the paramagnetic probe- $T_{I}$ method (about 15\%). In addition, this results might also indicate that the N3 at the pyrimidine ring interacts with the enzyme, as found in other pterin binding proteins as chicken liver dihydrofolate reductase in which a glutamic acid side chain forms hydrogen bonds to both N3 and exocyclic N2 of the pterin (29). In this context, the residue Glu332, located at the active site of TH (11) may be involved in the bind- ing of the pterin. This amino acid is conserved in the homologous enzyme phenylalanine hydroxylase, in which it has been shown to be of critical importance for pterin binding (30).

In addition to the substitutions on the tetrahydropterin ring, the $\mathrm{C} 6$ chirality and the conformation of the side-chain at $\mathrm{C} 6$ seem to be critical for the affinity and the regulatory properties of the cofactor $(1,2,31)$. The conformation around the $\mathrm{Cl}^{\prime}-\mathrm{C} 2{ }^{\prime}$ in the dihydroxypropyl-side chain at $\mathrm{C} 6$ in $\mathrm{BH}_{4}$ has been found to be trans both by X-ray analysis (24) and theoretical calculations by the molecular-orbital method (32). Moreover, these hydroxyl groups in $\mathrm{BH}_{2}$ bound to 4a-hydroxycarbinolamine dehydratase are trans and only the 1 ' interacts with the protein through a hydrogen bond (33). For this enzyme, however, there are small effects of substitutions at C6 of the pterin on the catalytic efficiency of the enzyme (34). The data obtained in the present NMR study are consistent with these two hydroxyl groups in THl-bound $\mathrm{BH}_{2}$ being almostcis $\left(\Theta=-75^{\circ}\right.$ to $\left.-83^{\circ}\right)$, indicating that their conformation might be altered on binding to the enzyme. The hydroxyls in biopterin are also bound in almost-cis conformation to dihydrofolate reductase (29), an enzyme showing a narrow specificity for substitutions at C6 (35).

Due to the metal coordinating ability of the pterins, both in small pteridine-containing metal complexes $(36,37)$ and in the copper-inhibited phenylalanine hydroxylase of Chromobacterium violaceum (38), the possibility of a direct coordination of the pterins to the divalent metal in TH (iron in the active form) was considered. For all the conformers of $\mathrm{BH}_{2}$ or $6-\mathrm{MPH}_{4}$, the estimated distance between either the 4-oxo in the pyrimidine ring or the $\mathrm{N} 5$ in the pyrazine ring and the metal were 3.3-4.1 $\AA$ Although these distances indicate that a metal-pterin coordination is unlikely, the experimental error associated to the determination of absolute metal-proton distances prevents a definite conclusion.

It has been proposed that a 4a-hydroperoxytetrahydropterin, or a similar species also involving the iron atom at the active site, is the hydroxylating intermediate in the TH catalyzed reaction $(1,10)$, although this species has not been directly observed with any tetrahydropterin dependent enzyme. Both the pterin ring and the aromatic ring of L-Phe $((3)$ and this work) seem to be placed in the second coordination sphere of the metal in $\mathrm{TH}$, supporting a key role of the iron in the hydroxylation reaction. A dioxygen 
molecule bound to the iron forming a peroxo- or superoxo-iron species comes close $(<3 \AA)$ from both the $\mathrm{C} 4 \mathrm{a}$ atom in the pterin [the $4 \mathrm{a}$-hydroxytetrahydropterin is the first product of the reaction $(8-10)]$ and either the C3- or the C4-position of the aromatic ring of the substrate. The site of initial hydroxylation in the substrate is determined primarily by steric factors, with a ratio for addition at C4-versus C3-position of 24:1 for L-Phe as the substrate (39-40). Thus, the results of our structural studies are consistent with a hydroxylating species involving the active site iron in $\mathrm{TH}$, in agreement with recent kinetic data (40).

\section{Acknowledgments}

We are very grateful to Sidsel E. Riise for the purification of THI and to Ali S. Muñoz for preparation of bacterial extracts. Professor Jan Haavik is thanked for helpful discussions. This research was supported by grants from the Research Council of Norway and the European Commission (Contract No. BIO2CT-CT930074).

\section{References}

1. Kaufman S. Adv. Enzymol. 1995; 70: 103-220.

2. Kappock TJ, Caradonna, JP. Chem. Rev. 1996; 96 : 2625-2658.

3. Martínez A, Abeygunawardana C, Haavik J, Flatmark T, Mildvan AS. Biochemistry 1993; 32: 63816390 .

4. Grima B, Lamoroux A, Boni C, Julien J-F, JavoyAgid F, Mallet J. Nature 1987; 326: 21-26.

5. Haavik J, Le Bourdelles B, Martínez A, Flatmark T, Mallet J Eur. J. Biochem. 1991; 199: 371-378.

6. Haavik J, Martínez A, Olafsdottir S, Mallet J, Flatmark T. Eur. J. Biochem. 1992; 210: 23-31.

7. Dix TA, Kuhn DM, Benkovic SJ. Biochemistry 1987; 26: 3361-3368.

8. Haavik J, Flatmark T. Eur. J. Biochem. 1987; 168: 21-26.

9. Almås B, Haavik J, Flatmark T. Biochem. J. 1996; 319: 947-951.

10. Dix TA, Benkovic S J. Acc. Chem. Res. 1988; 21 : 101-107.

11. Goodwill KE, Sabatier C, Marks C, Raag R, Fitzpatrick PF, Stevens RC. Nature Struc. Biol. 1997; 4: 578-585.

12. Martínez A, Abeygunawardana C, Haavik I, Flatmark T, Mildvan AS. Adv. Exp. Med. Biol. 1993; 338: $77-80$.
13. Mildvan AS, Granot J, Smith GM, Liebman M. Adv. Inorg. Biochem. 1980; 2: 211-236.

14. Campbell AP, Sykes BD. Annu. Rev. Biophys. Biomol. Struct. 1993; 22: 99-122.

15. Lian LY, Barsukov IL, Sutcliffe MJ, Sze KH, Roberts GCK. Meth. Enzymol. 1994; 239: 657-700.

16. Pfleiderer W, Liedek E, Lohrmann R, Rukwied M. Chem. Ber. 1960; 93: 2015-2024.

17. Reinhard JFJr, Smith GK, Nichol CA. Life Sci. 1986; 39: 2185-2189.

18. Campbell AP, Sykes BD. J. Magn. Reson. 1991; 93: 77-92.

19. Campbell AP, Sykes BD. J. Mol. Biol. 1991; 222: 405-421.

20. Al-Karaghouli AR, Koetzle TF. Acta Crystallogr. 1975; B31: 2461-2465.

21. Havel TF. Biopolymers 1990; 29: 1565-1585.

22. Havel TF. Progr. Biophys. Mol. Biol. 1991; 56: 4378.

23. Almås $\mathrm{B}$, Le Bourdelles $\mathrm{B}$, Flatmark $\mathrm{T}$, Mallet $\mathrm{J}$, Haavik J. Eur. J. Biochem. 1992; 209: 249-255.

24. Matsuura S, Sugimoto $T$, Murata $S$, Sugawara $Y$, Iwasaki H. J. Biochem. 1985; 98: 1341-1348.

25. Williams TC, Storm CB. Biochemistry 1985; 24: 458-466.

26. Bieri JH, Viscontini M. Helv. Chim. Acta 1977; 60: 447-453.

27. Bieri JH. Dev. Biochem. 1979; 4: 19-24.

28. Andersson KK, Haavik J, Martínez A, Flatmark T, Petersson L. FEBS Lett. 1989; 258: 9-12.

29. McTigue MA, Davies JF, Kaufman BT, Kraut. J. Biochemistry 1992; 31: 7264-7273.

30. Dickson PW, Jennings IG, Cotton RGH. J. Biol. Chem. 1994; 269: 20369-20375.

31. Bailey SW, Dillard SB, Ayling JE. Biochemistry 1991; 30: 10226-10235.

32. Katoh S, Sueoka T, Kurihara T. Pteridines 1993; 4: 27-31.

33. Cronk JD, Endrizzi JA, Alber T. Prot. Sci. 1996; 5: 1963-1972.

34. Rebrin I, Bailey SW, Boerth SR, Ardell MD, Ayling JE. Biochemistry 1995; 34: 5801-5810.

35. Smith GK, Banks SD, Bigham EC, Nichol CA. Arch. Biochem. Biophys. 1987; 254: 416-420.

36. Kohzuma T, Masuda H, Yamauchi O. J. Am. Chem. Soc. 1989; $111: 3431-3433$.

37. Odani A, Masuda $\mathrm{H}$, Inukai $\mathrm{K}$, Yamauchi O. J. Am. Chem. Soc. 1992; 114: 6294-6300.

38. Pember SO, Benkovic SJ, Villafranca JJ, Pasenkiewicz-Gierula M, Antholine WE. Biochemistry 1987; 26: 4477-4483.

39. Fitzpatrick PF. J. Am. Chem. Soc. 1994; 116 : 11331134.

40. Hillas PJ, Fitzpatrick PF. Biochemistry 1996; 35: 6969-6975. 